\title{
Altered pattern of insulin receptor isotypes in skeletal muscle membranes of Type 2 (non-insulin-dependent) diabetic subjects
}

\author{
M.Kellerer ${ }^{1}$, G. Sesti ${ }^{2}$, E. Seffer ${ }^{1}$, B. Obermaier-Kusser ${ }^{1}$, D. E. Pongratz ${ }^{3}$, L. Mosthaf ${ }^{1}$, H. U.Häring ${ }^{1}$ \\ ${ }^{1}$ Institut für Diabetesforschung, Munich, Germany \\ ${ }^{2}$ Universita di Roma, Dipartimento di Medicina Interna, Rome, Italy \\ ${ }^{3}$ Friedrich-Baur Institut, Munich, Germany
}

Summary. The human insulin receptor exists in two isoforms (HIR-A $\alpha$-subunit 719 amino acids and HIR-B $\alpha$-subunit 731 amino acids) which are generated by alternative splicing of a small exon and display distinct patterns of tissue-specific expression. Using the polymerase chain reaction we have recently shown that skeletal muscle of non-diabetic individuals contains predominantly mRNA encoding HIR-A while in skeletal muscle derived from subjects with Type 2 (non-insulin-dependent) diabetes mellitus similar amounts of each mRNA are expressed. We used a polyclonal antibody which discriminates between HIR-A and HIR-B to assess the isoform expression at the protein level. The antibody showed clearly distinct displacement of insulin binding in skeletal muscle membranes of non-diabetic subjects compared to Type 2 diabetic subjects (displacement of specific ${ }^{125}$ I-insulin binding: 13 non-diabetic subjects $70.0 \% \pm 14.34,12$ Type 2 diabetic subjects $32.6 \% \pm 17.45$ ). A control antibody which does not discriminate between both isoforms showed similar displacement of ${ }^{125}$ I-insulin in membranes of non-diabetic and Type 2 diabetic subjects. These data suggest that the altered expression of receptor isotype mRNA in the skeletal muscle of Type 2 diabetic subjects leads to an altered receptor isoform pattern in the plasma membrane. While skeletal muscle membranes of non-diabetic subjects contain predominantly HIR-A, membranes of Type 2 diabetic subjects show an increased level of HIR-B in addition to HIR-A.

Key words: Insulin receptor isotypes, Type 2 (non-insulindependent) diabetes mellitus, insulin receptor antibody.
The human insulin receptor occurs in two isoforms which differ in the length of the receptor $\alpha$-subunit $[1,2]$. The two isoforms arise from tissue-specific alternative splicing of a small exon (exon 11) encoding 12 amino acids [3-5]. Despite some different properties of HIR-A and HIR-B [5-9] it is unclear whether the receptor isoforms have different cellular functions. In a recent report [10] we found an alteration of the insulin-receptor isoform transcripts in the skeletal muscle of Type 2 diabetic subjects. This result is controversially discussed as other studies do not confirm this observation $[11,12]$. In our study analysis of mRNA revealed the existence of both receptor transcripts in diabetic subjects in contrast to healthy control subjects who showed exclusive to predominant expression of the receptor A transcript. We found an analogous alteration in a subsequent study where we analysed the receptor transcripts in skeletal muscle of insulin-resistent nondiabetic individuals [13]. The aim of the present study was to assess the impact of the altered transcript level on the distribution of the receptor isoforms in the plasma membranes of skeletal muscle of non-diabetic and Type 2 diabetic subjects. We were able to distinguish between the two receptor variants by employing a polyclonal antibody which displaces insulin from the receptor isoform-A with high affinity but not from the isoform-B [14]. When we measured the competition of this antibody with insulin binding to plasma membranes of well-characterized skeletal muscle from Type 2 diabetic and non-diabetic control subjects, we found a significant shift towards the receptor isoform-B. The data suggest that the altered pattern of polymerase chain reaction products of Type 2 diabetic and normal control subjects is parallelled by an altered pattern of insulin-receptor isoforms in the plasma membrane.

\section{Materials and methods}

Plastic material for tissue culture was from Greiner, (Frickenhausen, FRG), DMEM Nutrimix F12 and fetal calf serum were from Gibco, (Eggenstein, FRG). Porcine insulin was from Sigma, (Munich, FRG), $A^{14}$ - $\left({ }^{125}\right.$ I)monoiodoinsulin from New England Nuclear, (Bad Homburg, FRG). All other reagents were of the best grade commercially available. Antibody (Ab) I-2 was derived from the serum of a patient who had systemic lupus erythematosus and hypoglycaemia 


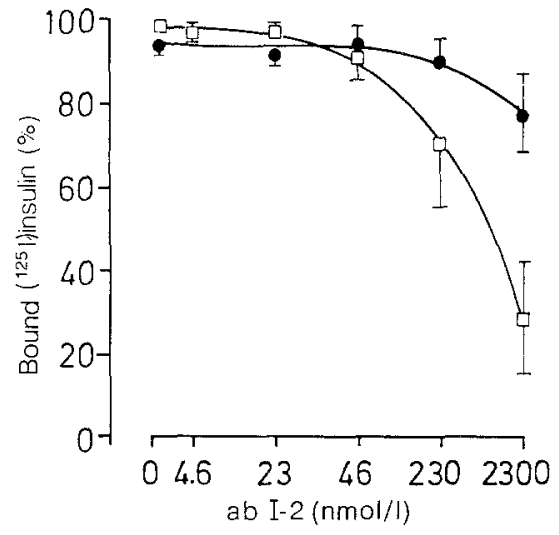

Fig. 1. Effect of $1-2$ antibody on ${ }^{125}$ I-insulin binding to rat-1 fibroblasts. Fibroblasts transfected with HIR-A $(\square-\square)$ or HIR-B $(-)$ ) were incubated with ${ }^{125} \mathrm{I}$-insulin and the indicated amounts of the polyclonal antibody I-2. Non-specific binding was determined in the presence of $1 \mu \mathrm{mol} / \mathrm{l}$ unlabelled insulin and was substracted. Mean values of three separate experiments (duplicates) and $\mathrm{SD}$ are shown
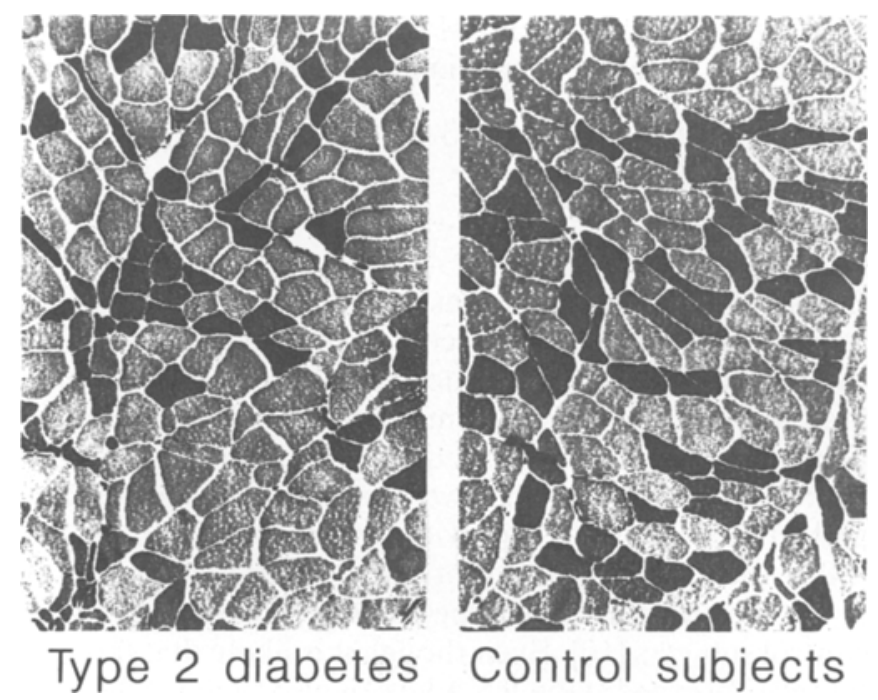

Type 2 diabetes Control subjects

Fig. 2. Characterization of human skeletal muscle samples. A representative enzyme histochemical preparation from non-diabetic (right) and diabetic (left) m. gastrocnemius $(100 \times)$. The tissue was stained with myofibrillic ATPase ( $\mathrm{pH}$ 9.4). The bright cells are type I (red) muscle fibres, and the dark cells are type II (white) muscle fibers

due to insulin-receptor autoantibodies. The antibody recognizes only type A human insulin-receptor with high affinity [14]. Ab 83-14 binds to the $\alpha$-subunit of the insulin receptor and was characterized earlier [15].

\section{Cell culture}

Rat-1 fibroblasts transfected either with HIR-A or with HIR-B were cultured in DMEM F12 supplemented with $10 \%$ fetal calf serum, $2 \mathrm{mmol} / \mathrm{lglutamine}, 50 \mu \mathrm{g} / \mathrm{ml}$ penicillin, and $50 \mu \mathrm{g} / \mathrm{ml}$ streptomycin at $37^{\circ} \mathrm{C}$ and $5 \% \mathrm{CO}_{2}$. After reaching confluence cells were washed three times with a Krebs Ringer Hepes buffer ( $\mathrm{pH} 7.4)$ and were removed from the culture plates with a rubber policeman for further studies.

\section{Tissue samples}

Tissue specimens of musculus gastrocnemius were obtained from non-obese Type 2 diabetic and non-diabetic 60 to 80 -year-old subjects who had undergone leg amputation due to peripheral arteriovascular complications. Informed consent was obtained from all the subjects. All samples were taken from the musculus gastrocnemius immediately after operation, cut into small pieces, rapidly frozen in liquid nitrogen and stored at $-80^{\circ} \mathrm{C}$.

Methods for histological, histochemical and morphological examination as well as for measuring muscle enzyme activities have been previously described in detail $[16,17]$.

\section{Plasma membrane preparation of human muscle}

Plasma membranes were prepared from human muscle as described earlier [17-19] by a differential centrifugation method with modifications described by Karnieli et al. [20]. The reproducibility of the fractionation procedure was assessed by measuring the oubain-sensitive $\mathrm{Na} / \mathrm{K}^{+}$ATPase (enriched in the plasma membrane fraction) [21]. The membrane protein assay was performed by the Coomassie brillant blue method (Bio-Rad assay).

\section{Binding studies}

Transfected rat-1 fibroblasts or plasma membranes from human muscle were incubated with $0.003 \mathrm{nmol} / 1$ of ${ }^{125} \mathrm{I}$-insulin and various concentrations of $\mathrm{Ab} \mathrm{I}-2$ as indicated in Figures. The incubation was done at $4^{\circ} \mathrm{C}$ for $14 \mathrm{~h}$ in a Krebs Ringer Hepes buffer containing $2.5 \%$ bovine serum albumin ( $\mathrm{pH} 7.4)$. Non-specific binding was determined by adding excess unlabelled insulin $(1 \mu \mathrm{mol} / \mathrm{l})$ to the samples. Cells and plasma membranes respectively were separated from the free ${ }^{125} \mathrm{I}$-insulin by centrifugation and washing three times with the incubation buffer. The amount of ${ }^{125} \mathrm{I}$-insulin bound to the receptor was determined in a gamma-counter.

For $\mathrm{Ab}$ 83-14 binding cells were incubated for $1 \mathrm{~h}$ with the antibody, then washed three times and incubated with $0.003 \mathrm{nmol} / \mathrm{l}$ ${ }^{125} \mathrm{I}$-insulin with or without unlabelled insulin $(1 \mu \mathrm{mol} / 1)$. Separation from free ${ }^{125}$ I-insulin was done as described.

\section{Results}

The specificity of the polyclonal antibody against the insulin receptor was assessed as described recently by Sesti et al. $[14,22]$. To standardize the effect of the I-2 antibody on ${ }^{125} \mathrm{I}$-insulin binding to the two receptor isoforms we used rat-1 fibroblasts expressing either HIR-A or HIR-B. Figure 1 shows the displacement of ${ }^{125}$ I-insulin by different concentrations of the polyclonal antibody I-2. The antibody displaced ${ }^{125}$ I-insulin from HIR-A up to $71.6 \% \pm 13.7{ }^{125}$ I-insulin binding to HIR-B is not significantly displaced by addition of the antibody. To control the specificity of this antibody we performed binding studies with a mouse monoclonal antibody 83-14 [15] which is able to prevent insulin binding to the $\alpha$-subunit of the insulin receptor. This antibody does not discriminate between the receptor isoforms in the plasma membrane preparation (insulin binding after $\mathrm{Ab}$ 83-14 incubation was $43 \% \pm 10.4$ for HIR-A and $49 \% \pm 8.6$ for HIR-B, compared to maximal insulin binding without $\mathrm{Ab} 83-14$ ).

Samples of musculus gastrocnemius from Type 2 diabetic and non-diabetic control subjects were studied. The muscle samples were characterized by fibre composition as well as light microscopic, electron microscopic and 

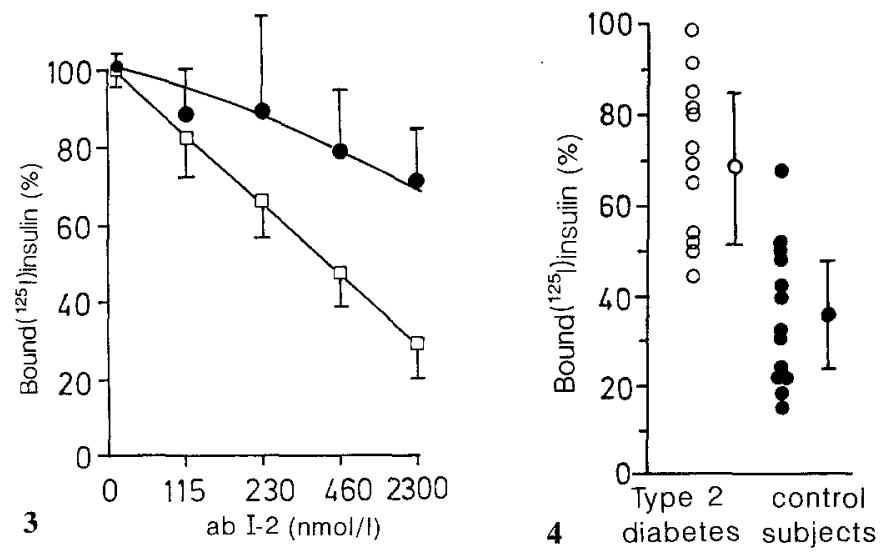

Fig.3. Effect of $\mathrm{I}-2$ antibody on ${ }^{125} \mathrm{I}$-insulin binding to plasma membranes of human muscle. Plasma membranes from skeletal muscle of subjects with Type 2 diabetes $(\bullet)$ ) and control subjects $(\square-\square)$ were prepared as described in the methods section. Plasma membranes ( $\approx 50 \mu \mathrm{g}$ protein/sample) were incubated with ${ }^{125} \mathrm{I}$-insulin and $\mathrm{Ab} \mathrm{I}-2$ as indicated. Non-specific binding was determined in the presence of $1 \mu \mathrm{mol} / 1$ unlabelled insulin and was subtracted. Mean values and SD of five samples from Type 2 diabetic subjects and six control subjects are shown

Fig. 4. Maximal effect of $\mathrm{I}-2$ antibody on ${ }^{125} \mathrm{I}$-insulin binding to plasma membranes from human skeletal muscle from Type 2 diabetic and control Subjects. Maximal displacement of ${ }^{125} \mathrm{I}$-insulin was measured in plasma membranes from skeletal muscle as described in Figure 2 and in the methods section. In both groups (Type 2 diabetes and control subjects) displacement was maximal at the highest antibody concentration ( $2300 \mathrm{nmol} / \mathrm{l})$. Individual values of plasma membrane samples from 12 Type 2 diabetic and 13 control subjects are shown. Beside the individual distribution mean values and SD of both groups are indicated

enzymatic (phosphofructo kinase, lactate dehydrogenase, phosphoglycerate kinase, phosphoglucomutase) criteria. Figure 2 shows the fibre composition of the selected muscle samples which was determined histologically. There was no difference in fibre composition, number and size between the diabetic and non-diabetic group (Fig.2). Only muscle samples which show no difference in all of the above-mentioned criteria have been used for our study. There was also no difference in muscle enzyme activities between non-diabetic and Type 2 diabetic subjects (Table 1). The clinical characteristics of the non-diabetic and Type 2 diabetic group are shown in Table 2.

A plasma membrane enriched fraction was prepared from muscle samples to study the effect of the antibody on insulin binding in skeletal muscle. To ensure that comparable qualities of the membranes were obtained we measured the activity of $\mathrm{Na} / \mathrm{K}^{+}$ATPase which is enriched in plasma membranes. Comparable values were found in membranes from control and Type 2 diabetic subjects (oubain sensitive $\mathrm{Na} / \mathrm{K}^{+}$ATPase Type 2 diabetic subjects: 115.3 \pm 35.0 ; control: $119.4 \pm 48.5 \mathrm{nmol} \mathrm{P}_{\mathrm{i}} \cdot \mathrm{min}^{-1} \cdot \mathrm{mg}^{-1}$ of protein). In agreement with earlier findings in solubilized receptor preparations (data not shown) there was no difference in specific insulin binding to the plasma membranes of either the Type 2 diabetic or non-diabetic control subjects. Furthermore, in both plasma membrane preparations non-specific insulin binding was similar. Figure 3 shows the displacement curves for ${ }^{125} \mathrm{I}$-insulin bind- ing to plasma membranes of skeletal muscle from six normal and five Type 2 diabetic subjects. The antibody I-2 clearly shows a more pronounced displacement of insulin from control membranes compared to Type 2 diabetic membranes (Type 2 diabetic: $29.4 \% \pm 13.6$, control: $71.1 \% \pm 9.2$; half-maximal displacement was in both groups at $230 \mu \mathrm{mol} / 1 \mathrm{Ab} \mathrm{I}-2$ ). The relative displacement at the respective antibody concentration (percent of maximal effect) was similar in both groups (Fig.3). We studied then displacement at the maximal effective antibody concentration in 13 control and 12 Type 2 diabetic subjects. In Figure 4 maximal displacement as percent of the specific insulin binding is plotted for 12 Type 2 diabetic and 13 control subjects. There is a high individual variation in both groups, however, a significant difference $(p<0.01$, Student's $t$-test) of the displacement pattern between both groups is evident. To control binding on plasma membranes from human skeletal muscle we performed binding with $\mathrm{Ab}$ 83-14. In contrast to the I-2 antibody, with the 83-14 antibody no discrimination between the Type 2 diabetic and the non-diabetic group could be demonstrated (insulin binding after $\mathrm{Ab}$ 83-14 incubation was $43 \% \pm 8.7$ for control and $41 \% \pm 6.2$ for Type 2 diabetic subjects, compared to maximal insulin binding without Ab 83-14).

\section{Discussion}

Insulin receptor preparations from different tissues have revealed structural and functional differences [1-9]. Although post-translational modifications of the receptor are the likely reasons for some of these different properties, others could be a consequence of the tissue-specific expression pattern of the two receptor isoforms HIR-A and HIR-B. We have previously demonstrated at the mRNA level clearly different isotype expression patterns in the skeletal muscle of Type 2 diabetic and non-diabetic control subjects [10]. Even though it is likely that this difference observed at the RNA level is also found at the protein level, proof for this is still lacking. Since translation efficiency or half-lives could be different for the two transcripts, we decided to determine the relative proportion of insulin receptor variants in the plasma membrane of skeletal muscle. We determined the human insulin receptor isoform expression with a specific antibody which discriminates between HIR-A and HIR-B with respect to competition to ${ }^{125} \mathrm{I}$-insulin binding as described by Sesti et al. [14, 22]. Using this antibody recent studies could also demonstrate a difference in the insulin receptor isoform distribution in human adipose tissue of diabetic subjects [22] compared to non-diabetic subjects. Unfortunately, the antibody neither recognizes the solubilized HIR-A on Western blot nor does it immunoprecipitate solubilized HIR-A.

The binding curves which are derived from plasma membranes of rat- 1 fibroblasts overexpressing HIR-A or HIR-B demonstrate that the antibody is able to displace approximately $70 \%$ of the specifically bound ${ }^{125} \mathrm{I}$-insulin from HIR-A while only a non-significant displacement of ${ }^{125} \mathrm{I}$-insulin binding is seen in HIR-B. The degree of dis- 
placement observed with the antibody in membranes expressing both receptor isotypes might to a certain extent reflect the relative contribution of the isotypes to total ${ }^{125} \mathrm{I}-$ insulin binding. The data demonstrate that membranes from non-diabetic control subjects and membranes from Type 2 diabetic subjects yield a wide variation of individual displacement values. As expected for membranes expressing predominantly the receptor isoform A normal control subjects show, with the exception of two individuals, a displacement of at least $50 \%$ of ${ }^{125} \mathrm{I}$-insulin binding. In contrast, plasma membrane preparations from Type 2 diabetic subjects show a smaller degree of displacement. In some subjects almost no displacement was detectable suggesting that in this case the receptor isoform $\mathrm{B}$ predominantly contributes to the total ${ }^{125}$ I-insulin binding. Extrapolating the mean values of the binding data on the insulin receptor isoform expression the non-diabetic group shows a distribution of $7: 3$ HIR-A:HIR-B, whereas the Type 2 diabetic group revealed an almost opposite relation of $3: 7 \mathrm{HIR}-\mathrm{A}$ :HIR-B. These findings are in contradiction to recent reports by Benecke et al. and Hansen et al. $[11,12]$. These groups found no difference of insulin receptor isotype expression between Type 2 diabetic and non-diabetic subjects. Benecke et al. [11] studied the isoform-pattern of five Type 2 diabetic patients and five control subjects both at the mRNA and at the protein level while the data by Hansen et al. [12] refer only to the mRNA-transcripts and not to protein level of HIR-isoforms. There are several possible explanations for this discrepancy. Muscle samples were derived from different sources i.e. from biopsies of $m$. vastus lateralis and $m$. rectus abdominis $[3,11]$ or from $\mathrm{m}$.gastrocnemius in our studies. However, we think this is an unlikely explanation as we could reproduce our initial observation of altered transcript levels in a recent study where we analysed vastus lateralis biopsies of 25 individuals with different levels of insulin sensitivity [13]. Another possible reason for dif-

Table 1. Muscle enzyme activities and non-collagen protein levels for subjects admitted to the study

\begin{tabular}{lcc}
\hline Enzyme & $\begin{array}{l}\text { Non-diabetic } \\
\text { subjects }\end{array}$ & $\begin{array}{l}\text { Type 2 diabetic } \\
\text { patients }\end{array}$ \\
\hline Lon-collagen-protein (U/g) \\
Lactate dehydrogenase & $1267 \pm 98$ & $1203 \pm 76$ \\
Phosphofructo kinase & $124 \pm 13$ & $136 \pm 13$ \\
Phosphoglycerate kinase & $798 \pm 87$ & $883 \pm 111$ \\
Phosphoglucomutase & $977 \pm 94$ & $1085 \pm 121$ \\
\hline Non-collagen protein & $81 \pm 17$ & $76 \pm 14$ \\
(mg/g muscle) & & \\
\hline
\end{tabular}

The enzyme activities were measured twice for each patient as described recently [19]. The units of activity were normalized for noncollagen protein fering results could be a contamination of muscle tissue with other tissues. In particular a cross contamination with fat in biopsies might give rise to artefacts in the polymerase chain reaction. As fat contains both receptor isoforms a contamination of the muscle biopsies will lead to the appearance of both receptor transcripts. Since the material used in our study was morphologically characterized we can exclude any cross contamination with non-muscle tissue. Another important factor might be differences in insulin levels and in the metabolic status of the different Type 2 diabetic groups in these studies. Furthermore, the number of subjects examined in the study is another important issue. While Benecke et al. [11] draw their conclusions from only five individuals in each group, we analysed 12 Type 2 diabetic and 13 non-diabetic subjects. In agreement with our data at the protein level they found a high individual variation of the insulin receptor isoform expression pattern. Although two of five Type 2 diabetic subjects showed an increased abundance of HIR-B and in addition the mean values indicate an increase in the HIR-B expression of Type 2 diabetic subjects, these results have not been considered significant. In agreement with the authors who propose that more muscle samples have to be examined to clarify whether HIR-B expression is increased in Type 2 diabetic subjects, we think that this effect might be more profound if more subjects were included in the study. In our analysis we examined more muscle samples and found a significant shift towards HIR-B expression in the Type 2 diabetic group compared to the non-diabetic group. However, looking at the individual results we found an overlap for at least five subjects between both groups. Although our present data support the results of the earlier mRNA determinations the pathophysiological meaning of these observations remain obscure. In our recent study [13] with another group of non-diabetic subjects with varying levels of insulin sensitivity it appeared that a decreased non-oxidative glucose disposal rate is associated with an increase of the transcript for HIR-B. This might suggest that this phenomenon is not a consequence of the metabolic derangements observed in Type 2 diabetic subjects but is rather a phenomenon linked to muscle insulin resistance.

Acknowledgements. We thank T.Dull (Genentech) and Prof. D. A. McClain (UCSD) for constructing the HIR-A and HIR-B expression plasmid and transfection into Rat- 1 cells. We are indebted to Prof. A. Ullrich for continuous support.

\section{References}

1. Ullrich A, Bell JB, Chen EY et al. (1985) Human insulin receptor and its relationship to the tyrosine kinase family of oncogenes. Nature 313: 756-761

Table 2. Characteristics of the subjects studied

\begin{tabular}{|c|c|c|c|c|c|c|}
\hline & \multirow[t]{2}{*}{$n$} & \multirow{2}{*}{$\begin{array}{l}\text { Age } \\
\text { (years) }\end{array}$} & \multicolumn{2}{|c|}{ Fasting serum } & \multirow{2}{*}{$\begin{array}{l}\mathrm{Hb} / \mathrm{A}_{1_{\mathrm{C}}} \\
(\%)\end{array}$} & \multirow[t]{2}{*}{ Insulin-treated } \\
\hline & & & $\begin{array}{l}\text { Glucose } \\
(\mathrm{mmol} / \mathrm{l})\end{array}$ & $\begin{array}{l}\text { Insulin } \\
(\mu \mathrm{U} / \mathrm{ml})\end{array}$ & & \\
\hline Control subjects & 13 & $66 \pm 4.3$ & $5.5 \pm 0.6$ & $14.7 \pm 5.3$ & $5.35 \pm 0.35$ & none \\
\hline
\end{tabular}


2. Ebina Y, Ellis L, Jarmagin K et al. (1985) The human insulin receptor c-DNA: the structural basis for hormone-activated transmembrane signalling. Cell 46: 747-758

3. Moller DE, Yokota A, Caro JF, Flier JS (1989) Tissue-specific expression of two alternatively spliced insulin receptor mRNAs in man. Mol Endocrinology 3: 1263-1269

4. Seino S, Bell GI (1989) Alternative splicing of human insulin receptor messenger RNA. Biochem Biophys Res Commun 159: 312-316

5. Mosthaf L, Grako D, Dull TJ et al. (1990) Functionally distinct insulin receptors generated by tissue-specific alternate splicing. EMBO J 9:2409-2413

6. Kellerer M, Lammers R, Ermel B et al. (1992) Different $\alpha$-subunit structures of the human insulin receptors type $A$ and $B$ affect the tyrosine kinase activity of the $\beta$-subunit. Biochemistry 19: 4588-4596

7. Vogt B, Carrascosa J, Ermel B et al. (1991) The two isotypes of the human insulin receptor (HIR-A and HIR-B) follow different internalization kinetics. Biochem Biophys Res Commun 177: 1013-1018

8. McClain D (1991) Different ligand affinities of the two human insulin receptor splice variants are reflected in parallel changes in sensitivity for insulin action. Mol Endo 5: 734-739

9. Yamaguchi Y, Flier JS, Yokota A et al. (1991) Functional properties of two naturally occurring isoforms of the human insulin receptor in chinese hamster ovary cells. Endocrinology 129: 20582066

10. Mosthaf L, Vogt B, Häring HU, Ullrich A (1991) Altered expression of insulin receptor types $A$ and $B$ in the skeletal muscle of non-insulin-dependent diabetes mellitus subjects. Proc Natl Acad Sci USA 88: 4728-4730

11. Benecke H, Flier JS, Moller DE (1992) Alternatively spliced variants of the insulin receptor protein. Expression in normal and diabetic human tissues. J Clin Invest 89: 2066-2070

12. Hansen T, Bjorback C, Vestergaard H, Bak JF, Pedersen O (1992) Alternatively spliced variants of the insulin receptor and its functional correlates in muscle from patients with type 2 diabetes and normal subjects. Diabetologia 35: A76

13. Mosthaf L, Eriksson J, Häring HU et al. (1993) Insulin receptor isotype expression correlates with risk of non-insulin-dependent diabetes. Proc Natl Acad Sci USA 90: in press

14. Sesti G, Marini MA, Montemurro A et al. (1992) The two naturally occurring human insulin receptor forms are immunologically distinct. Diabetes 41:6-11
15. Soos MA, Siddle K, Baron MD et al. (1986) Monoclonal antibodies reacting with multiple epitopes on the human insulin receptor. Biochem J 235: 199-208

16. Obermaier-Kusser B, White MF, Pongratz DE et al. (1989) A defective intramolecular autoactivation cascade may cause the reduced kinase activity of the skeletal muscle insulin receptor from subjects with non-insulin-dependent diabetes mellitus. J Biol Chem 264: 9497-9503

17. Vogt B, Mühlbacher C, Carrascosa J et al. (1992) Subcellular distribution of GLUT 4 in skeletal muscle of lean type 2 (non-insulin-dependent) diabetic subjects in the basal state. Diabetologia 35: 456-463

18. Mühlbacher C, Karnieli E, Schaff P et al. (1988) Phorbol esters imitate in rat fat-cells the full effect of insulin on glucose-carrier translocation, but not on 3-0-methylglucose-transport activity. Biochem J 249: 865-870

19. Obermaier-Kusser B, Mühlbacher Ch, Mushack J et al. (1988) Regulation of glucose carrier activity by $\mathrm{AlCl}_{3}$ and phospholipase C in fat cells. Biochem J 256:515-520

20. Karnieli E, Zarnowski MJ, Hissin PJ et al. (1981) Preparation and characterization of plasma membrane fraction from isolated rat fat cells. J Biol Chem 256: 4772-4777

21. Avruch J, Wallach DEH (1971) Erythrocyte membrane adenosine triphosphate activities in subjects with endogenous depression and healthy subjects. Biochem Biophys Acta 233: 334-347

22. Sesti G, Marini MA, Tullio AN et al. (1991) Altered expression of the two naturally occurring human insulin receptor variants in isolated adipocytes of non-insulin-dependent diabetes mellitus subjects. Biochem Biophys Res Commun 181:1419-1424

Received: 30 November 1992

and in revised form: 1 March 1993

Prof. H.U.Häring

Institut für Diabetesforschung

Kölner Platz 1

W-8000 München 40

Germany 